\title{
Editorial: Business Model Innovation in Air Transport Management - Selected papers from the IFSPA 2015, Hong Kong, 2015
}

The air transport industry operates in a highly competitive, dynamic and complex environment. The past few years have witnessed a number of innovative business models such as dual brand strategy (running a full service airline and a low-cost carrier in the same airline group); low-cost long haul operations; airline cross-border joint ventures; vertical integration between airports and airlines; and the growing importance of ancillary revenue for airlines. As these new business models are continuously evolving, they may potentially change the landscape of the air transport industry.

The importance of innovation relating to sustainable air transport cannot be overstated. In this day and age, air transport operations need to tackle the challenge of striving for environmental performance whereby a balance between geographic changes (e.g. changes in population distribution, changes of spatial connections, and changes of hub locations) and environmental protection is increasingly expected in the society. Business model innovation is now seen as a solution to many of the issues that we are facing. Furthermore, the world's economic development is closely associated with the development of air transport and its spatial network. While the airline industry faces strong competition from other modes of transport, particularly, high speed rail, there is also the emergence of cooperation between airlines and high speed rail in some countries. The continued growth of integrated transport modes appears to be critical for economic development at the regional and national level.

Against this background, the "International Forum on Shipping, Ports and Airports 2015" (IFSPA) was held in Hong Kong, from 29 November to 2 December 2015. The conference, first started in 2007 , has achieved growing success in recent years. It is designed to be a general platform for academic researchers and industry practitioners to examine important issues related to shipping, ports, and airports. IFSPA is an annual conference for international academies and practitioners to discuss and exchange views on contemporary issues related to global maritime and aviation economies, policy and amangement. In 2015 this conference attracted over 100 participants with 48 presentations. Following a double-blind review process, the guest editors have chosen seven papers to be included in this special issue of the 
Journal of Air Transport Management. The papers provide readers with excellent insights into business model innovation in the airline industry.

The first two papers examine the business model of low-cost carriers (LCCs), while the third paper looks into the network airlines. The fourth paper performs a case study of two hybrid airlines and the fifth paper examines business charter. The sixth paper studies an interdependent business model for airline-airport coexistence. Finally, the seventh paper examines the simulation model of security control system functioning using Wroclaw Airport as a case study.

In the first paper, Wang, Tsui, Liang and Fu analyzed route entry patterns of LCCs in Hong Kong using two alternative models, namely a standard probit model and a generalized least squares estimation. Consistent findings from the two models suggested that LCCs in Asia had a preference for large markets with big populations, high incomes and high traffic volume, but government regulations and airport access were main impediment factors. The authors argued that it is important for governments in the region to liberalize aviation markets, provide sufficient airport capacity, and promote efficient allocation of airport slots so as to benefit the tourism industry and overall economy.

In the second paper, Chen investigated the competitive responses of China Eastern to the entry of Spring Airlines into its hub airports in Shanghai. The analysis takes into account of the actual and adjacent competition for both LCCs and full-service airlines (FSAs) within an airport-pair framework. The results of the econometric analysis showed that Spring put downward pressure on the average fares of China Eastern and other FSAs. But China Eastern responded more aggressively than other FSAs to Spring's competition on routes from the same and nearby airports. Having said that, the moderate price reduction of $4 \%$ to $4.9 \%$ suggests that China Eastern did not perceive Spring as a serious competitor. Chen argued that such limited impacts were due to restrictions imposed by the government onto Spring Airlines in terms of capacity control and access to major trunk routes.

In the third paper, Redpath, O'Connell and Warnock-Smith investigated two of the largest network carriers, Lufthansa Group and Emirates Group, each adopting a distinct approach 
towards diversification that may serve as a model for airline groups worldwide. The areas investigated were Cargo, Maintenance, Catering and Travel Services. The research found that whilst diversification may not always present the most attractive option financially, strategic factors can often outweigh such concerns. Business units studied were found to have variable prospects; particularly in the case of Catering, a sector on the rise - versus in-house Maintenance, which for airlines, is likely to see decline. The pursuit of third party revenue streams to offset weak internal trading and growth in competencies were found to be the key drivers of success. Interplay between segments was also apparent, showing that a wellorganized diversification strategy can achieve robust cross-functional benefits and deliver significant value to the parent organization.

In the fourth paper, Corbo examined the rise of the hybrid business model to the traditional business model dichotomy between low-cost and full-service carriers and questions its viability as an alternative for growth and profitability. Using a comparative assessment of business model innovation practices of two established carriers, Air Berlin and JetBlue. The results suggested that, following the transition from a no-frills to a hybrid business model, a misalignment between the value proposition and the other elements of the business model will hinder an airline's ability to achieve a sustainable competitive advantage.

In the fifth paper, Yen and Chen investigated business travelers' choice behavior between business charter and the business class of commercial airlines in the cross-strait market. The study applied the stated preference method and set five scenarios with the combination of various levels of fares, waiting time, privacy, expedient clearance services, and inflight communication equipment. Results indicated that fare was the most important factor. Other factors such as gender, seniority, and the number of business trips during the previous year were significant on the probabilities of choosing business charter. Additionally, five specific features of business charter set as dummy variables in the model, namely, transfer time saving, travel time controlling, client entertainment, customer visits and international conference attendance, all having positive effects on the preference for using business charter. 
In the sixth paper, Minato and Morimoto examined a case where an airline and an airport agreed on the guaranteed flight load factor. The model was calibrated using data from 2003 to 2014 for Noto Airport and All Nippon Airways, and system dynamics were employed to model the dynamic interactions between the two parties. The findings showed that successful coexistence between an airline and an airport hinges on the integral management of annual negotiations regarding the target load factor and the monthly demand adjustment of subsidies. In addition, although a subsidy represents a temporary financial loss for an airport, it is an effective way of maintaining long-term, airline-airport coexistence.

In the last paper, Kierzkowski and Kisiel presented an airport security control model. The algorithm allows to establish a capacity lack margin in the security control system in order to lower the costs of the system's operation and to maintain a quality of passenger service at an acceptable level. The model was implemented at Wroclaw Airport for the management of security checkpoint. The results showed that the model performed well and can be used in existing security control systems as well as being used to evaluate the operation of a system being designed.

The important role of business model innovation is highlighted in this Special Issue. Air transport and aviation logistics have been growing in the logistics industry. Further advancement is still undergoing. Although traditional practice of air transport services is still important, business model innovation is emerging the aviation logistics markets, especially because of the booming of e-commerce and the expansion and upgrading of air transport infrastructure. The advent of the era of advanced technologies (e.g. mobile internet, big data, cloud computing) provides a new data sources to passengers, travellers and all stakeholders.

The business model innovation is the driving force of the logistics industry as a whole and is leading the current reform and future development of the air transport industry. This Special Issue is timely to promote more research on the business model innovation in the air transport and aviation logistics. The industry begins to realize the significance of being more innovative in air transport management. The ability to be more innovative will help to catch up with the quick development of the industry. As extensions of this Special Issue, some 
interesting issues are yet to be addressed. For example, the passengers' awareness on business model innovation and their choices are not known. It is also crucial for researchers to share not only new knowhow but also innovative practice.

We sincerely thank the participants of the IFSPA 2015 in Hong Kong for thought provoking discussions in the paper sessions, the authors and referees for their contribution to this IFSPA Special Issue of the Journal of Air Transport Management. The encouragement and guidance provided by the Editors-in-Chief, Dr Anne Graham and Prof Sveinn Gudmundsson during the editing process are gratefully acknowledged. 


\section{Editorial}

Business Model Innovation in Air Transport Management - Selected papers from the IFSPA 2015, Hong Kong, 2015

Tsz Leung Yip ${ }^{1 *}$, Zheng Lei $^{2}$, John F. O'Connell ${ }^{3}$

${ }^{1}$ Hong Kong Polytechnic University, Hong Kong. Email: t.l.yip@polyu.edu.hk

* Corresponding guest editor

2 University of Surrey, United Kingdom. Email: zheng.lei@surrey.ac.uk

${ }^{3}$ Cranfield University, United Kingdom. Email: frankie.oconnell@cranfield.ac.uk

Research Highlights

This special issue focuses on business model innovation in air transport management

The selected papers demonstrates a wide range of innovation in air transport business.

The special issue emphasizes the evolution and the importance of innovation in air transport management. 


\section{Editorial}

Business Model Innovation in Air Transport Management - Selected papers from the IFSPA 2015, Hong Kong, 2015

Tsz Leung Yip ${ }^{1 *}$, Zheng Lei $^{2}$, John F. O'Connell ${ }^{3}$

${ }^{1}$ Hong Kong Polytechnic University, Hong Kong. Email: t.l.yip@polyu.edu.hk

* Corresponding guest editor

2 University of Surrey, United Kingdom. Email: zheng.lei@surrey.ac.uk

${ }^{3}$ Cranfield University, United Kingdom. Email: frankie.oconnell@cranfield.ac.uk 
2017-02-08

\section{Editorial: Business model innovation in air transport management-Selected papers from the IFSPA 2015, Hong Kong, 2015}

Yip, T. L.

Elsevier

Yip TL, Lei Z, O'Connell JF, Editorial: Business model innovation in air transport management-Selected papers from the IFSPA 2015, Hong Kong, 2015, online 8 February 2017, DOI: 10.1016/j.jairtraman.2017.01.005

http://dx.doi.org/10.1016/j.jairtraman.2017.01.005

Downloaded from Cranfield Library Services E-Repository 